\title{
Efficacy of Comprehensive Ayurveda Management of Vertebral Disc Lesions (Asthyasrayee Vata) by Panchakarma Therapies and Herbomineral Formulations
}

\section{Research article}

\author{
Narayan. S. Jadhav ${ }^{1 *}$, Vinod D.Patange ${ }^{2}$, Vilasrao K.Jagatap ${ }^{3}$, Anantkumar Shegokar ${ }^{4}$ \\ 1*Associate Prof. \& H.O.D. Department of Rognidan \& Vikruti Vidnyan. Dhanwantri \\ Ayurveda Medical College \& Hospital, UDGIR Dist:- Latur ( MS) INDIA \\ 2. Assistant Professor, 3. Professor and HOD, \\ Department of Dravyaguna, ,Department of Dravyaguna, \\ S C M Aryangla Vaidyak Mahavidyalaya,I T I Road,Satara-415002(M.S.) \\ 4. Associate Professor and HOD, Dept of Shalyatantra, \\ VNH'S Ayurved Medical College ,Rahuri.(M.S.)
}

\begin{abstract}
The Vertebral disc lesions affect nearly $80 \%$ of the people at some point in their lives like, spondylosis (Cervical/Thoracic/Lumbar) and PID. It is the most common causes of job related disability leading to missed work and the second most common neurological ailment. Raised incidence of these disorders are observed probably resulted from extensive vehicular riding, uneven roads, irregular dietetic habits, irregular postures, insufficient sleep, injuries to vertebras, leads to loss of cushion action in between vertebral bodies. Many times patients get moderate to severe pain in lumbar or cervical region. It affects day to day activities and also leads to incurable problems like spondylolithiasis, spinal canal stenosis, sacralization, Cauda Equina Syndrome etc., which has drawn attention of researchers and scientist.

In charak samhita sutra sthan the importance of Samshodhan Chikitsa has been mentioned. Taking these things in to consideration efforts have been made to treat the patients of vertebral disc lesions with Panchakarma therapy and Herbomineral Formulations.

On the basis of findings and observations obtained after completion of current project it can be concluded that vertebral disc lesions are progressive degenerative conditions in which vata at its own Ashaya (Asthi-Sandhi) gets provoked and as it belongs to Madhyam Rogamarga treatment becomes challenging .

Comprehensive Ayurveda management of vertebral disc lesions by panchkarma therapies and herbomineral formulations. This attempt possibly finds solutions which can delay or even prevent surgical intervenation as Sandhis are sites of Marma. It is an effective, simple, safe treatment modality for vertebral disc lesion.
\end{abstract}

\section{Keywords:- Vertebral disc lesions, backache, Panchkarma, Samshaman}

*Corresponding Author:

Narayan. S. Jadhav,

Associate Prof. \& H.O.D.

Department of Rognidan \& Vikruti

Vidnyan.

Dhanwantri Ayurveda Medical College \& Hospital, UDGIR Dist:- Latur ( MS) INDIA Email:- drnarayanj52@gmail.com

\section{Introduction:-}

The Vertebral disc lesions affect nearly $80 \%$ of the people at some points in their lives like, spondylosis (Cervical/Thoracic/Lumbar) and PID. It is the most common causes of job related disability leading to missed work and the 
second most common neurological ailment.

Raised incidence of these disorders are observed probably resulted from extensive vehicular riding, uneven roads, irregular dietetic habits, irregular postures, insufficient sleep, injuries to vertebras, leads to loss of cushion action in between vertebral bodies. Many times patients get moderate to severe pain in lumbar or cervical region. It affects day to day activities and also leads to incurable problems like spondylolithiasis, spinal canal stenosis, sacralization, Cauda Equina Syndrome etc. Which has drawn attention of researchers and scientist. (2)

\section{Need of Study}

As per as other therapies of the disease is concerned, there is no established treatment except surgical intervention, even though, the patients are not getting completely cure on the contrary, many patients are getting reoccurrence. Laminectomy is also sometimes causes complications and side effects. Hence, patients are turning to Ayurveda for the treatment.

Considering the nature of conventional procedures, their complications and results.

An attempt has been made to evolve the treatment modality for the Degenerative spine pathologies. The study entitled "Efficacy of Comprehensive Ayurveda management of Vertebral disc lesions by Panchkarma therapies and Herbomineral formulations."

With this background a study based on basic principles of treatment of Ayurveda is proposed i.e.

Shodhanam shamanam samasadaushadham dvidha. ( C.Su.1/25) Shodhanam:- Shamanam :-

The curative detoxification which aims to purify the human body from organ to cellular level \& to clear various channels of the body to enable free flow of nutrients, metabolites \& medicine. Thus it is the radical treatment of the disease in which vitiated Dosha are eradicated or eliminated and then completely preventing or curing the disease Pacification or palliative management of disease by administration of drug and diet.

It is claimed that a disease cured by samashodhana never relapse or re-occur, as this therapy eradicates the "very root cause of disease", but the disease treated by Shamanam may relapse or re-occur as it is conservative line of treatment.(3)

Basic Principle of Treatment:

In every disease it is said to follow following lines of treatment

1. Deepan

2. Pachana

Then, come to the main disease i.e. Vertebral disc lesion (Asthyashryanam Vyadhi) the following quotation is useful Asthyashryanam

Vyadhinam

Panchkarmani Bheshajam.

Bastya Kshir Sarpishi Tiktakop Hitanicha. (C.Su.28/27)

Vertebral disc lesion can be divided in to cervical spondylosis and Lumbar spondylosis. For cervical spondylosis the nearest way to remove vitiated dosha is mukha hence we can give vaman to these patients and for lumbar spondylosis nearest way to remove dosha is Gud so we have to give virechan in these cases(4). Kshirbasti will be common in both conditions as this is bruhan basti. As per the above quotation Tikta Kshir Basti should be given in all ashyasrayee vyadhis. Nasya can be given in both conditions because all the neurological activities comes under Shira and as Nasa hi shiraso Dwaram! We can give snehan by means of Nasya. Bruhan nasya can rejuvenate neurological system(5).

The Vertebral disc lesions are progressive degenerative conditions where vata at its own Ashaya (Asthi-sanshi) gets provoked and as its belong to Madhyamrogmarga6. The aim of the treatment should be to bring the vitiated 
dosha in Aamashaya by means of deepan,pachan,Valukaswdan,snehapan,ab hyanga and swedan. After vitiated dosha reaches the Amashaya panchakarma i.e. Vaman,Virechan,Basti, nasya etc are performed to remove the dosha out of the body. After Panchakarm, to avoid the relapse, samshaman therapy is suggested

This will be comprehensive approach incorporating panchkarma therapies and Herbo mineral formulations.

It is imperative to explore a therapeutics module to tackle these conditions \& possibly find solution that can delay or even prevent surgical intervention as sandhi are sites of marma.

\section{Aims \& Objective:-}

Present clinical work has been undertaken with the following objectives

1. To assess the classical concept of shodhana (panchakarma ) \& Shamana (Herbomineral) in the Management of Vertebral disc lesions(Asthyasrayee Vata).

2. To establish an effective, simple treatment modality for the management of vertebral disc lesions(Asthyasrayee Vata).

\section{Material and Methods:-}

The study was conducted in 100 clinically diagnosed patients of Cervical and Lumbar spondylosis, aged between 21 to 65 years. The study was carried out in the Dhanwantri Ayurved medical college and Hospital ,Udgir Dist.Latur.[M.S]

Study Design \& Duration: - The study design was open clinical trial over 100 cases of both cervical \& lumber spondylosis. The study was preliminary attempt to know the efficacy of Panchkarma \& Herbomineral formulations.

Duration of treatment :- 60 days
30 days for Udavartan, Valukasweda, Snehpanam, Abhyanga Swedhanam, Vaman, Virechanam, Basthi

30 days for Samshaman therapy to avoid relapse.

As per the selection criteria, all the patients were interviewed, examined and randomly selected and divided in to two groups.

Group I - Patients having cervical lesion were kept on Deepanam,Pachanam and Panchkarma (Udvartan and Valukasveda, Snehapan, Abhyanga \& Sweda, Vamankarma, Tiktksheer Basti, Greevabasti, Nasyakarma.)

Group II - Patients having lumbar lesion were kept on Panchkarma (Udvartan and Valukasveda, Snehapan, Abhyanga \& Sweda, Virechankarma, Tiktaksheer Basti, Katibasti, Nasyakarma.)

Patients of both groups were advised identical diet restrictions and life style changes i.e. (pathykar Aahar \& Vihar)

\section{Selection criteria:- Inclusion criteria:-}

Patients of either sex between 21 to 65 years on the basis of clinical signs and symptoms.

who are fit for Panchkarma (Vamankarma, Virechankarma, Basti \& Nasya).

\section{Exclusion criteria:-}

Patients with cervical \& Lumbar spondylosis with accompanying diagnosis of heart disease, critically ill patients, with neurological complications and who are unfit for Panchakarma. Patients on other therapies (allopathic, homeopathic or other than prescribed Ayurveda drugs) and who are not willing for this treatment protocol were excluded.

Written informed consent was obtained from each patient and the institutional ethical committee approved clinical protocol. 


\section{Diagnostic Criteria:-}

1. Classical symptomatology of Greevasthambh, Katigraha, Gridhrasi and Cardinal Symptoms of cervical \& lumbar spondylosis.

2. Radiological investigations:- $\mathrm{X}$ ray, MRI if required

3. Laboratory investigations:- CBC, BSL-F/PP, Urine R/M, Lipid profile.

4. E.C.G.

\section{Pre-treatment observations:-}

All the patients were studied along with the registration by noting their demographic profile like age, sex, occupation, education, socio-economical status, addictions, dietary habits etc. Detailed physical, General and Systemic examinations were performed. During this all other relevant information like Astavidha Pariksha, Dashavidha Pariksha including assessment of Sharir and Manas Prakriti was done as per textual references.

\section{Administration of Procedures, Drugs,} Dose \& Duration:-

1. Udvartan \& Valukasweda by Kottamchukkadi churna - 3 days.

2. Snehapan (Internal oleation) by plain Ghee - 3 to 5 days.

3. Abhyanga - (body massage ) by sesame oil.

4. Swedana - (Steam bath) By the Decoction of Dashmul

5. Procedure of Vamanakarma (Drug induced vomiting)

a) Selection of Vamanarha patients of cervical lesions for - Group I

b) Classical Vamankarma was performed and sansarjankrma (Diet restrictions) was followed for 3 days.

6. Procedure of Virechankarma (Drug induced purgation)

a) Selection of Virechanarha patients of lumbar lesions - for Group II b) Classical Virechankarma was performed and Sansarjan karma (Diet restrictions) was followed for 3 days.

7. BastiKarma (Medicated Enema):For both groups Titakasheerbasti was given for 7 days with quantity of $200 \mathrm{ml}$.

8. Nasya Karma (Nasal insufflations) :- For both groups Navan Nasya of Kalyanakghritha - 4 - 4 drops BID

9. Greeva Basti:- It was done in $\mathrm{I}^{\text {st }}$ group (cervical lesion) by sesame oil for 7 days

10. Kati Basti :- It was done in $\mathrm{II}^{\mathrm{nd}}$ group (lumbar lesion) by sesame oil for 7 days

11. Herbominerals:-Both groups were kept on oral drugs such as Tab. Arogyavardhini - $250 \mathrm{mg}$ BID, Tab. Panchtiktaghritha Guggulu $250 \mathrm{mg}$ BID with local Abhayanga and Nadisweda for 1 month.

\section{Criteria of Assessment:-}

During the trial and follow up study, the patients were assessed after completion of each treatment procedure and follow up was done.

\section{a) Subjective Improvement:-}

All the patients under trial were specially asked for any changes or improvement in their growing feeling of well being either physically or mentally and their clinical manifestations produced by the Panchakarma and administration of Herbo mineral drug under trial.

\section{b) Clinical Improvement:-}

All symptoms to be taken for the assessment of clinical improvement, the incidence of presenting features were worked out and the severity of the symptoms was rated in each case. In $\mathrm{I}^{\text {st }}$ group clinical signs and symptoms Cervical pain, Flatulence, Hyperacidity, Constipation, Poor appetite, Abdominal pain and in II $^{\text {nd }}$ group that of Back pain, 
Flatulence, Hyperacidity, Constipation, Numbness in legs, Pain in legs etc were recorded .
Observational Parameters:-

In the following tables the data is analyzed according to various parameters of observation and results shown.

Table 1: Incidence of type of vertebral disc lesions in 100 treated cases.

\begin{tabular}{|c|l|l|l|}
\hline Sr. No. & Lesion & No. of Patients & Percentage \\
\hline 1. & Cervical & 42 & 42 \\
\hline 2. & Lumbar & 58 & 58 \\
\hline 3. & Total & 100 & 100 \\
\hline
\end{tabular}

From the above table it has been noticed that cervical lesion were seen in 42 patients $(42 \%)$ where as lumbar lesion was seen in 58 patients $(58 \%)$

Table 2: Incidence of symptoms of cervical lesions of 42 treated cases

\begin{tabular}{|c|l|l|l|}
\hline Sr.No & \multirow{2}{*}{ Symptoms } & \multicolumn{2}{|c|}{ No. of Patients } \\
\cline { 3 - 4 } & & Before treatment & After treatment \\
\hline 1. & Cervical pain & $42(100 \%)$ & 0 \\
\hline 2. & Flatulence & $14(33.33 \%)$ & $4(9.52 \%)$ \\
\hline 3. & Hyperacidity & $18(44.44 \%)$ & $3(7.14 \%)$ \\
\hline 4. & Constipation & $14(33.33 \%)$ & $4(9.52 \%)$ \\
\hline 5. & Poor appetite & $05(11.11 \%)$ & 0 \\
\hline 6. & Abdominal pain & $02(5.5 \%)$ & 0 \\
\hline
\end{tabular}

Table 3: Incidence of symptoms of lumbar lesions of 58 treated cases

\begin{tabular}{|c|l|l|l|}
\hline \multirow{2}{*}{ Sr.No } & \multirow{2}{*}{ Symptoms } & \multicolumn{2}{|c|}{ No. of Patients } \\
\cline { 3 - 4 } & & Before treatment & After treatment \\
\hline 1. & Back pain & $58(100 \%)$ & $4(6.89 \%)$ \\
\hline 2. & Flatulence & $29(50 \%)$ & $2(3.44 \%)$ \\
\hline 3. & Hyperacidity & $05(8.51 \%)$ & $3(5.17 \%)$ \\
\hline 4. & Constipation & $34(59 \%)$ & $4(6.89 \%)$ \\
\hline 5. & Numbeness in legs & $11(20 \%)$ & $5(8.62 \%)$ \\
\hline 6. & Pain in legs & $20(34.04 \%)$ & $4(6.89 \%)$ \\
\hline
\end{tabular}

Table 4: Incidence of sex in both lesions of 100 cases

\begin{tabular}{|c|l|l|l|l|}
\hline Sr. No. & Lesion & Male & Female & Percentage \\
\hline 1. & Cervical & 28 & 14 & 42 \\
\hline 2. & Lumbar & 30 & 28 & 58 \\
\hline 3. & Total & 58 & 42 & 100 \\
\hline
\end{tabular}

Table 5: Incidence of Age group in both lesions of 100 cases

\begin{tabular}{|c|l|l|l|l|}
\hline Sr.No & Age group & Cervical & Lumbar & Percentage \\
\hline 1. & $21-30$ & 07 & 11 & 18 \\
\hline 2. & $31-40$ & 18 & 26 & 44 \\
\hline 3. & $41-50$ & 13 & 19 & 32 \\
\hline 4. & $51-60$ & 01 & 03 & 04 \\
\hline 5. & $60 \&$ above & 01 & 01 & 02 \\
\hline
\end{tabular}


Table 6: Incidence of Occupation in both lesions of 100 cases

\begin{tabular}{|c|l|l|l|l|}
\hline Sr. No. & Occupation & Male & Female & Percentage \\
\hline 1. & Hard work & 22 & 13 & 35 \\
\hline 2. & Moderate work & 18 & 14 & 32 \\
\hline 3. & Sedentary lifestyle & 18 & 15 & 33 \\
\hline 4. & Total & 58 & 42 & 100 \\
\hline
\end{tabular}

Table 7: Incidence of Chronicity in both lesions of 100 cases

\begin{tabular}{|c|l|l|l|l|}
\hline Sr. No. & Chronicity (in Years) & Male & Female & Percentage \\
\hline 1. & $1-3$ & 27 & 18 & 45 \\
\hline 2. & $3-6$ & 23 & 16 & 39 \\
\hline 3. & $6-10$ & 03 & 04 & 07 \\
\hline 4. & $10 \&$ above & 05 & 04 & 09 \\
\hline 5. & Total & 58 & 42 & 100 \\
\hline
\end{tabular}

Table 8: Overall clinical response (Total result) of cervical lesions of 42 cases

\begin{tabular}{|c|l|l|l|}
\hline Sr. No. & Clinical resoponse & No. of Patients & Percentage \\
\hline 1. & Complete relief & 30 & 71.42 \\
\hline 2. & Marked relief & 07 & 16.66 \\
\hline 3. & Moderate relief & 05 & 11.90 \\
\hline 4. & Not responded & 00 & 00 \\
\hline 5. & Total & 42 & 100 \\
\hline
\end{tabular}

Table 9: Overall clinical response (Total result) of lumbar lesions of 58 cases

\begin{tabular}{|c|l|l|l|}
\hline Sr. No. & Clinical resoponse & No. of Patients & Percentage \\
\hline 1. & Complete relief & 30 & 51.72 \\
\hline 2. & Marked relief & 17 & 29.31 \\
\hline 3. & Moderate relief & 11 & 18.96 \\
\hline 4. & Not responded & 00 & 00 \\
\hline 5. & Total & 58 & 100 \\
\hline
\end{tabular}

\section{Discussion:}

Vertebral disc lesions are compared with Vatvyadhi in Ayurveda. These diseases are included in Asthomahagada (difficult to cure) \& having Madhyam Roga marg (Intermediate root of diseases) after lot of advancement in the field of modern medicine these problems are still remaining a challenge.

The characteristic features observed during these studies are

Overall clinical response of cervical lesions of 42 cases are found complete relief in $30(71.42 \%)$, marked relief $07(16.66 \%)$ moderate relief 05 $(11.90 \%)$ cases \& that of lumbar lesion of
58 cases are found complete relief in 30 $(51.72 \%)$ marked relief $17 \quad(29.31 \%)$ moderate relief $11(18.96 \%)$.

The clinical features In $\mathrm{I}^{\text {st }}$ group Cervical pain, Flatulance $(71 \%)$, Hyperacidity (83\%), Constipation(71\%), Poor appetite(100\%), Abdominal pain $(100 \%)$ and in $\mathrm{II}^{\text {nd }}$ group that of Back pain(93\%), Flatulance(93\%), Hyperacidity(40\%), Constipation( $88 \%)$, Numbness in legs, Pain in legs etc were found to be improved significantly.

Probable mode of action of different Panchkarma procedures:

1. Udvartan \& Valukasweda:- These are preparatory procedures for snehan and 
swedan. as Manyastambha and Katistambha are Upasthambhit vatavyadhi for deepan and pachan these procedures are useful.So,this will be amaj vyadhi and it should require Deepan and Pachan 7

2. Snehapan (Internal oilation):- It pacifies vata also dosha shithilikaranat

3. Abhyanga \& Swedana :-Vitiated dosha comes to Aamashaya

4. Vamanakarma :- it removes vitiated doshas which comes to Aamashaya and may acts as internal traction and cause internal muscle pulling also Can be helpful in nerve root compression due to its Kaphaharatava property \& improves IV space reduction

5. Virechankarma :- it removes vitiated adhobhaga doshas which are coming to Mahasrotas after Udavartan, Valukaswed, snehapanam, A bhyanga and swedanam

6. Basti Karma:- It acts as Antidegenerative, it nourishes to Asthi Dhatu, strengthens musculature

7. Nasya Karma:- It is a faster way to reach the head and nourishes to Brain which is sthan of Pran (Pranah pranbhutam shirasah) 8

8. Greeva Basti \& Kati Basti:- It pacifies Vat and reduces local pain

9. Herbominerals

A) Arogyavardhini - 250 mg BID9

B) Panchtiktaghrut guggulu - $250 \mathrm{mg}$ BID10

\section{Observations \& Results:}

The incidence of vertebral disk lesion was found to be grater in age group of 30-50 years where cervical $31 \&$ lumbar 45.

The clinical features $\mathrm{In} \mathrm{I}^{\mathrm{st}}$ group Cervical pain, Flatulance, Hyperacidity, Constipation, Poor appetite, Abdominal pain and in II $^{\text {nd }}$ group that of Back pain, Flatulance, Hyperacidity, Constipation, Numbness in legs, Pain in legs etc were found to be improved significantly
Incidence of sex in both lesions were male 58 (cervical 28 \& lumbar 30 ) while in female 42 (cervical $14 \&$ lumbar 28)

It is observed that there are various factors which cause vertebral lesions, excessive travelling on vehicles, excessive movements of Neck, like clerical work, computer work, Prakriti, Age, occupation are having an impact on these conditions.

The lower grade of sara, samhanan, sattva may also play some role in causing these conditions.

\section{Side / adverse effects:}

None of the patients of both groups reported any side effect and no specific complications were recorded during and after the course of treatment.

\section{Conclusion:}

On the basis of findings and observations obtained after completion of current project it can be concluded that vertebral disc lesions are progressive degenerative conditions in which vata at its own Ashaya (Asthi-Sandhi) gets provoked and as it belongs to Madhyam Rogamarga treatment becomes challenging .

Comprehensive Ayurveda management of vertebral disc lesions by panchkarma therapies and herbomineral formulations.This attempt possibly finds solutions which can delay or even prevent surgical intervenation as Sandhis are sites of Marma.

It is an effective, simple, safe treatment modality for vertebral disc lesion.

\section{Acknowledgements:}

The author wish to thank Dr. P. Mohankumar, Ex. Prof \& H.O.D., Department of Shalyatantra, Vaidyaratnam Ayurveda college, Ollur, Dist Thrissur, Kerala. Dr. P. Yadaiah, Prof. \& H.O.D., PG Department of Kayachikitsa, R.T. Ayurveda college, Akola (M.S.) \& Dr. S. Bhosle, Associate Prof. \& H.O.D. 
Department of Kayachikitsa, GAC, Nanded, (M.S.) for their constants support.

\section{References:}

1. CharakSamhita,Commentary by Chakrapanidatta, Choukhamba Sanskrit Samsthan,Varanasi, prathamo Bhaga, seventh edition,2002.p225

2. Sanjore S. \& Yadiah P., original research article, Modern interpretation of Greevastambha \& Manyastambha. Published in, National seminar on Vatavyadhis, at GOA, India, $24^{\text {th }} \& 25^{\text {th }}$ January 2004

3. CharakSamhita,Commentary by Chakrapanidatta, Choukhamba Sanskrit Samsthan, Varanasi, prathamo Bhaga, seventh edition,2002.p257

4. CharakSamhita,Commentary by Chakrapanidatta, Choukhamba Sanskrit Samsthan, Varanasi, prathamo Bhaga, seventh edition,2002.p43

5. CharakSamhita,Commentary by Chakrapanidatta, Choukhamba
Sanskrit Samsthan, Varanasi, prathamo Bhaga, seventh edition,2002.p85

6. CharakSamhita,Commentary by Chakrapanidatta ,Choukhamba Sanskrit Samsthan, Varanasi, prathamo Bhaga, seventh edition,2002.p167

7. CharakSamhita,Commentary by Chakrapanidatta, Choukhamba Sanskrit Samsthan, Varanasi, prathamo Bhaga, seventh edition,2002.p296

8. CharakSamhita,Commentary by Chakrapanidatta, Choukhamba Sanskrit Samsthan, Varanasi, prathamo Bhaga, seventh edition,2002.p85

9. Ras tantra sar sidhha prayog Samgrah -vol $1,15^{\text {th }}$ edition,june 2001, Krushnagopal Ayurved Bhavan,kaleda ,page no 500

10. Ras tantra sar sidhha prayog Samgrah - vol $\quad 1,15^{\text {th }} \quad$ edition,june 2001,krushnagopal ayurved 